American J. of Engineering and Applied Sciences 2 (4): 796-803, 2009

ISSN 1941-7020

(C) 2009 Science Publications

\title{
Improved Continuing Losses Estimation Using Initial Loss-Continuing Loss Model for Medium Sized Rural Catchments
}

\author{
Mahbub Ilahee and Monzur Alam Imteaz \\ Faculty of Engineering and Industrial Sciences, \\ Swinburne University of Technology, Hawthorn, Melbourne, VIC 3122, Australia
}

\begin{abstract}
Problem statement: The rainfall based design flood estimation techniques are commonly adopted in hydrological design and require a number of inputs including information on soil loss characteristics. Approach: A conceptual loss model known as the 'Initial Loss-Continuing Loss (ILCL) model' is widely used in Australia. Results: The Initial Loss (IL) occurs at the beginning of the rainfall event, prior to the commencement of surface runoff and the Continuing Loss (CL) is the average rate of loss throughout the remainder of the storm. The currently recommended design loss values depicted in "Australian Rainfall and Runoff Vol. 1" for Queensland (Australia) has some basic limitations. This study investigated how more accurate CL values can be estimated and derived for medium sized tropical Queensland catchments using long term rainfall and streamflow data. Accuracy in CL estimation has got significant implications in the estimation of design floods. Conclusion/Recommendations: The results showed that CL value is not fixed and constant through out the duration of the storm but the CL value decays with the duration of the storm.
\end{abstract}

Key words: Initial loss, continuing loss, rural catchments, flood estimation, rainfall-runoff modeling

\section{PROBLEM STATEMENT}

Flood estimation is often required in hydrologic design and has important economic significance ${ }^{[2]}$. Flood estimation and risk analysis in Australia involves an annual spending of the order of $\$ 650$ million $^{[4]}$. Rainfallbased flood estimation techniques are most commonly adopted and often require several inputs/parameters to convert design rainfalls to design floods ${ }^{[6,8]}$. Of the many inputs/parameters, the concept "loss" is an important parameter. Loss is the amount of precipitation that does not appear as direct runoff. Factors pertaining to loss in effect reduce the runoff during a flood event ${ }^{[2,7]}$.

In design flood estimation, simplified lumped conceptual loss models are commonly used because of their simplicity and ability to approximate catchment runoff behavior. Secondly, the detailed parameters needed for calculating individual loss components are generally not available. This is particularly true for design loss which is probabilistic in nature and for which complicated theoretical models may not be required. The common loss factors include rainfall intercepted by vegetation (interception loss), infiltration into the soil (infiltration), retention on the surface (depression storage), evaporation and loss through the streambed and banks. As these loss components are dependent on topography, soil characteristics, vegetation and climate; the components exhibit a high degree of temporal and spatial variability during high rainfall events. Many loss models do not account for the interception, depression storage and evaporation losses separately. Instead, such losses are considered as infiltration into the soil. In Australia, the most commonly adopted conceptual loss model is the initial loss-continuing loss model ${ }^{[1,4,6]}$. The initial loss occurs prior to the commencement of surface runoff and can be considered to be composed of the interception loss, depression storage and infiltration that occur before the soil surface is saturated. In design rainfall events, the continuing loss is computed as the average rate of loss that occurs up to the end of the rainfall event, after the initial loss is satisfied.

Selection of catchments: This study was aimed at deriving new improved design losses for Queensland catchments. A total of 48 unregulated rural catchments were selected from the entire state of Queensland. The selection of catchments was done based on the catchment size, regulation, record lengths of rainfall and streamflow data. However, from these primarily selected catchments, final selection of catchments was done based on location of the pluviograph station, daily rainfall station, streamflow gauging station and the catchment boundary.

Corresponding Author: Monzur Imteaz, Faculty of Engineering and Industrial Sciences, Swinburne University of Technology, Hawthorn, Melbourne, VIC 3122, Australia 
Catchment area: A primary selection parameter was size of the catchment; small or large. The loss (IL-CL) model which was used in this research is only suitable for small to medium size catchments and not suitable to compute the loss values for the larger catchments. The reason is that the process of computing loss values for larger catchments is different from the process of computing loss values for smaller catchments. It was observed that for larger catchments there is lack of uniformity in catchment characteristics than in smaller to medium sized catchments. Laurens on and Pilgrim ${ }^{[5]}$ mentioned that catchment characteristic is a factor which affects the loss value. Australian Rainfall and Runoff $^{[4]}$ suggests the catchment area with an upper limit of $1000 \mathrm{~km}^{2}$ can be considered as a small to medium sized catchments, which was taken as a guide to selecting the study catchments.

Regulation: To select the study catchments, consideration was given to whether the study catchments were regulated or unregulated, as major regulation affects the natural rainfall-runoff relationship significantly. Gauging stations subject to major regulation (such as dams, gates, diversions and back water effect) were not included in this study. Also urbanization affects the catchment hydrology, so no urban catchment was selected. Only unregulated rural catchments were selected for this study. Topographic Maps of Australia (1:100000) were consulted to investigate the nature of streamflow network and nature of regulation in the selected catchments. Also the gauging authority was consulted to know about any recent changes of regulation and land use in the selected catchments.

Record length: It was aimed to have significantly longer record lengths for the length of the rainfall and streamflow data of the catchments under study, as more number of rainfall and streamflow events will produce more reliable results. Among collected data, the highest record length of streamflow data is 48 years and the lowest record length of streamflow data is 11 years. The mean and median values of streamflow record length are 30 and 31 years. A total of 132 pluviograph stations and 338 daily rainfall stations were selected from and near the selected catchments. The rainfall data were obtained from the Bureau of Meteorology (BoM), Australia.

Catchment boundary: All the 48 catchment boundaries were collected from the Department of Natural Resources and Mines in electronic format. Mapinfo Professional 5.0 was used to delineate the catchment boundary for the selected catchments.

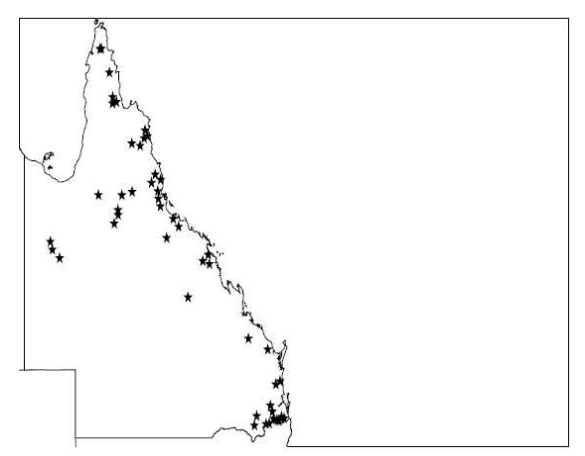

Fig. 1: Map of Queensland showing catchment locations

After mapping the catchment boundary, an electronic layer of stream gauging stations were laid over the catchment boundary. The catchments whose location of the stream gauging station in the map was found away from the catchment boundary, that catchment was not selected as study catchment. Catchments were selected, when there was one or more pluviograph station or daily rainfall stations within the catchment boundary. To select a rainfall streamflow event to estimate loss values the temporal pattern of the rainfall over the catchment is necessary. Catchments with only one pluviograph station but no daily rainfall station within the catchment boundary were selected as candidate catchments. As the catchments were small to medium in size, it was assumed that the temporal pattern of the pluviograph data was the representative temporal pattern of the whole catchment, provided the pluviograph station was located well inside the catchment boundary. But catchments with no pluviograph station inside or within $50 \mathrm{~km}$ of the catchment boundary were not selected as study catchments, though there was daily rainfall station within or near the catchment boundary. Again catchments having a pluviograph station close to the boundary and with daily rainfall stations within the catchment boundary were selected as study catchments. Because, it was assumed that when the pluviograph station and daily rainfall station are closely located, the temporal pattern of the daily rainfall station and the pluviograph station were same. Hence the pluviograph data can be used to proportion the daily rainfall data to obtain the representative temporal pattern of rainfall within the catchment.

The distribution of the candidate catchments selected from all over the Queensland is shown in Fig. 1. The locations of the study catchments were identified by the electronic layer of catchment boundaries with in the Queensland boundary using Mapinfo Professional. 
Am. J. Engg. \& Applied Sci., 2 (4): 796-803, 2009

Table 1: Stream gauge station number, location, catchment area and streamflow record length of the study catchments

\begin{tabular}{|c|c|c|c|c|c|c|c|c|}
\hline $\begin{array}{l}\text { Sr. } \\
\text { No. }\end{array}$ & Basin ID & Streamflow name & $\begin{array}{l}\text { Location of stream } \\
\text { gauging station }\end{array}$ & $\begin{array}{l}\text { Lat. of stream } \\
\text { gauge }\end{array}$ & $\begin{array}{l}\text { Long. of } \\
\text { stream gauge }\end{array}$ & $\begin{array}{l}\text { Catchment } \\
\text { area }\left(\mathrm{km}^{2}\right)\end{array}$ & $\begin{array}{l}\text { Start date of } \\
\text { streamflow }\end{array}$ & $\begin{array}{l}\text { Finish date } \\
\text { of streamflow }\end{array}$ \\
\hline 1 & $102101 \mathrm{~A}$ & Pascoe river & Fall creek & 12.87 & 142.97 & 635 & $1 / 10 / 1967$ & Continue \\
\hline 2 & $104001 \mathrm{~A}$ & Stewart river & Telegraph road & 14.17 & 143.38 & 480 & 18/01/1970 & $"$ \\
\hline 3 & $105105 \mathrm{~A}$ & E. Norman by river & Development road & 15.77 & 145.00 & 300 & $24 / 02 / 1969$ & " \\
\hline 4 & $107001 \mathrm{~B}$ & Endeavour river & Flaggy & 15.42 & 145.05 & 310 & $1 / 10 / 1967$ & $"$ \\
\hline 5 & 107003A & Anna river & Beesbike & 15.68 & 145.20 & 247 & 9/03/1990 & $"$ \\
\hline 6 & $112003 \mathrm{~A}$ & N. Johnston river & Glen allyn & 17.37 & 145.65 & 173 & $1 / 10 / 1958$ & $"$ \\
\hline 7 & 112101B & S. Johnston river & Upstream central meal & 17.60 & 145.97 & 400 & $1 / 10 / 1974$ & $"$ \\
\hline 8 & $114001 \mathrm{~A}$ & Murray river & Upper murray & 18.10 & 145.80 & 155 & $26 / 05 / 1970$ & $"$ \\
\hline 9 & 116008B & Gowrie creek & Abergowrie & 18.43 & 145.83 & 124 & $1 / 10 / 1953$ & $"$ \\
\hline 10 & $116015 \mathrm{~A}$ & Blunder creek & Wooroora & 17.73 & 145.43 & 127 & $20 / 10 / 1966$ & $"$ \\
\hline 11 & $116017 \mathrm{~A}$ & Stone river & Running creek & 18.77 & 145.95 & 157 & $30 / 06 / 1970$ & $"$ \\
\hline 12 & 118003A & Bohle river & Hervey range road & 19.32 & 146.70 & 143 & $1 / 04 / 1985$ & $"$ \\
\hline 13 & $119006 \mathrm{~A}$ & Major creek & Damsite & 19.67 & 147.02 & 468 & $4 / 05 / 1978$ & $"$ \\
\hline 14 & $120014 \mathrm{~A}$ & Broughton river & Oak meadows & 20.17 & 146.32 & 182 & $5 / 11 / 1970$ & $13 / 04 / 1999$ \\
\hline 15 & 120216A & Broken river & Old racecourse & 21.18 & 148.43 & 78 & $1 / 06 / 1969$ & $"$ \\
\hline 16 & $124002 \mathrm{~A}$ & St. Helens creek & Calen & 20.90 & 148.75 & 129 & $7 / 02 / 1973$ & $"$ \\
\hline 17 & $125005 \mathrm{~A}$ & Blacks creek & Whitefords & 21.32 & 148.82 & 505 & $12 / 12 / 1973$ & $"$ \\
\hline 18 & 130207A & Sande creek & Clermont & 22.78 & 147.57 & 409 & $21 / 01 / 1965$ & $"$ \\
\hline 19 & $136108 \mathrm{~A}$ & Monal creek & Upper monal & 24.60 & 151.10 & 92 & $15 / 07 / 1962$ & " \\
\hline 20 & $137101 \mathrm{~A}$ & Gregory river & Burrum highway & 25.08 & 152.23 & 454 & $10 / 02 / 1966$ & $"$ \\
\hline 21 & 138110A & Mary river & Bellbird creek & 26.62 & 152.70 & 486 & $1 / 10 / 1959$ & $"$ \\
\hline 22 & $141009 \mathrm{~A}$ & N. Maroochy river & Eumundi & 26.48 & 152.95 & 38 & $15 / 02 / 1982$ & $"$ \\
\hline 23 & $143110 \mathrm{~A}$ & Bremer river & Adams bridge & 27.82 & 152.50 & 125 & $30 / 09 / 1968$ & $"$ \\
\hline 24 & $143212 \mathrm{~A}$ & Tenhill creek & Tenhill & 27.55 & 152.38 & 447 & $18 / 03 / 1968$ & $"$ \\
\hline 25 & 145003B & Logan river & Forest home & 28.20 & 152.77 & 175 & $1 / 10 / 1953$ & $"$ \\
\hline 26 & $145010 \mathrm{~A}$ & Running creek & $5.8 \mathrm{~km}$ Deickmans bridge & 28.23 & 152.88 & 128 & $26 / 11 / 1965$ & " \\
\hline 27 & 145011A & Teviot brook & Croftby & 28.13 & 152.57 & 83 & $7 / 02 / 1966$ & $"$ \\
\hline 28 & $146014 \mathrm{~A}$ & Back creek & Beechmont & 28.12 & 153.18 & 7 & $5 / 06 / 1971$ & $"$ \\
\hline 29 & 145101D & Albert river & Lumeah number 2 & 28.05 & 153.03 & 169 & $1 / 10 / 1953$ & $"$ \\
\hline 30 & $416410 \mathrm{~A}$ & Macintyre brook & Barongarook & 28.43 & 151.45 & 465 & $15 / 06 / 1967$ & $"$ \\
\hline 31 & $422321 \mathrm{~B}$ & Spring creek & Killarney & 28.35 & 152.32 & 35 & $1 / 10 / 1972$ & $"$ \\
\hline 32 & $422338 \mathrm{~A}$ & Canal creek & Leyburn & 28.02 & 151.58 & 395 & $27 / 03 / 1972$ & $"$ \\
\hline 33 & $422394 \mathrm{~A}$ & Cadamine river & Elbow vally & 28.37 & 152.13 & 325 & $2 / 12 / 1972$ & $"$ \\
\hline 34 & $913005 \mathrm{~A}$ & Paroo creek & Damsite & 20.33 & 139.52 & 305 & $20 / 11 / 1968$ & $1 / 10 / 1988$ \\
\hline 35 & 913009A & Gorge creek & Flinders highway & 20.68 & 139.63 & 248 & $13 / 11 / 1970$ & Continue \\
\hline 36 & $915205 \mathrm{~A}$ & Malbon river & Black Gorge & 21.05 & 140.06 & 425 & $1 / 10 / 1970$ & $1 / 10 / 1988$ \\
\hline 37 & $916002 \mathrm{~A}$ & Norman river & Strathpark & 19.53 & 143.25 & 285 & $1 / 10 / 1969$ & $30 / 09 / 1988$ \\
\hline 38 & $916003 \mathrm{~A}$ & Moonlight creek & Alehvale & 18.27 & 142.33 & 127 & $1 / 10 / 1969$ & $10 / 04 / 1989$ \\
\hline 39 & $917005 \mathrm{~A}$ & Agate creek & Cave creek junction & 18.93 & 143.47 & 228 & $1 / 07 / 1969$ & $30 / 09 / 1988$ \\
\hline 40 & 917007A & Percy river & Ortana & 19.15 & 143.48 & 445 & $2 / 09 / 1969$ & $30 / 09 / 1988$ \\
\hline 41 & 917107A & Elizabeth creek & Mount surprise & 18.13 & 144.30 & 585 & 23/07/1968 & Continue \\
\hline 42 & $917114 \mathrm{~A}$ & Routh creek & Beef road & 18.28 & 143.70 & 81 & $11 / 12 / 1972$ & $30 / 09 / 1988$ \\
\hline 43 & $919201 \mathrm{~A}$ & Palmer river & Goldfields & 16.10 & 144.77 & 530 & $11 / 12 / 1967$ & Continue \\
\hline 44 & 919205A & North palmer river & $4.8 \mathrm{~km}$ & 16.00 & 144.28 & 430 & $16 / 10 / 1973$ & $30 / 09 / 1988$ \\
\hline 45 & $921001 \mathrm{~A}$ & Holroyd river & Ebagoola & 14.23 & 143.15 & 365 & $19 / 01 / 1970$ & $17 / 05 / 1988$ \\
\hline 46 & $922101 \mathrm{~B}$ & Coen river & Racecourse & 13.95 & 143.17 & 166 & $10 / 11 / 1967$ & Continue \\
\hline 47 & $926002 \mathrm{~A}$ & Dulhunty river & Dougs pad & 11.83 & 142.42 & 325 & $18 / 11 / 1970$ & " \\
\hline 48 & $926003 \mathrm{~A}$ & Bertie creek & Swordgrass swamp & 11.82 & 142.50 & 130 & $10 / 11 / 1972$ & $"$ \\
\hline
\end{tabular}

Each study catchment is represented by a stream gauging station. A list of selected stream gauging stations numbers, streamflow names, location of stream gauging stations, latitude and longitude of stream gauging stations, catchment area and streamflow record length (start and finish date) is shown in Table 1.

\section{APPROACH}

Methodology (CL estimation): In $\mathrm{ARR}^{[4]}$ the continuing loss is defined as the loss that occurs at a constant rate after the commencement of the surface runoff. The procedure which was adopted in this analysis to compute the continuing losses was the same as the procedure adopted in $\mathrm{ARR}^{[4]}$ i.e., the continuing loss is the rate of loss that occurred during the remainder of the storm.

The rates of continuing loss are constant as recommended in $\mathrm{ARR}^{[4]}$, however in reality the value could be decreasing with the time depending upon the soil cover and duration of the storm. In this study, it was investigated whether continuing loss rate is constant in nature or decays with the duration of the storm. 
In this analysis Initial Loss and Continuing Loss (IL-CL) model was used to compute the initial loss and continuing loss values from the rainfall and streamflow events. $\mathrm{ARR}^{[4]}$ recommended design median initial losses ranging from 15.0-35.0 $\mathrm{mm}$ and design median continuing loss $2.5 \mathrm{~mm} \mathrm{~h}^{-1}$ for eastern catchments of Queensland. Similarly for western Queensland catchments, the recommended median continuing loss is $1.4 \mathrm{~mm} \mathrm{~h}^{-1}$. As per ARR recommendations, the design initial loss varies with the duration; however the design continuing loss does not vary with time but remain constant throughout the duration of the storm.

The water balance equation from the start of a rainfall event till the end of a runoff event may be expressed as:

$\mathrm{R}=\mathrm{IL}+\mathrm{CL} * \mathrm{t}+\mathrm{QF}$

Where:

$\mathrm{R}=$ Total rainfall of the event expressed in average depth of rainfall in $\mathrm{mm}$ over the catchment

$\mathrm{QF}=$ Quickflow, assumed to be resulted from the rainfall event, expressed in $\mathrm{mm}$

$\mathrm{t}=$ Time elapsed between the start of the surface runoff till the end of the rainfall event (h)

Since, QF is the total Streamflow (SFT) minus Baseflow (BF), Eq. 1 may be written as:

$\mathrm{R}=\mathrm{IL}+\mathrm{CL} * \mathrm{t}+\mathrm{SFT}-\mathrm{BF}$

where, both SFT and BF are expressed in mm.

As IL-CL model does not consider the temporal variability of losses. From Eq. 1 CL may be expressed as:

$\mathrm{CL}=(\mathrm{R}-\mathrm{IL}-\mathrm{QF}) / \mathrm{t}$

To estimate QF in Eq. 3, separation of base flow from total streamflow was required. A lower limit of $0.0 \mathrm{~mm} \mathrm{~h}^{-1}$ and an upper limit of $20.0 \mathrm{~mm} \mathrm{~h}^{-1}$ were imposed for the continuing loss computation and events outside of this range were excluded from this analysis. As continuing loss value more than $20.0 \mathrm{~mm} \mathrm{~h}^{-1}$, needs more detailed investigation.

\section{RESULTS}

The descriptive statistics of all the selected 969 rainfall streamflow events of IL and CL values are shown in Table 2. A total of 48 catchments were considered as for this analysis. The IL values range was 0.0-189.37 $\mathrm{mm}$ and the CL values range was 0.01$18.31 \mathrm{~mm} \mathrm{~h}^{-1}$ and the median IL values range was from
0.7- $71.77 \mathrm{~mm}$ and the median CL values range was from $0.71-5.8 \mathrm{~mm} \mathrm{~h}^{-1}$ respectively.

Table 2 shows that the derived continuing loss values for all the 48 selected catchments are from 0.01 $18.31 \mathrm{~mm} \mathrm{~h}^{-1}$ and median continuing loss values for all the 48 selected catchments are from 0.71-5.8 $\mathrm{mm} \mathrm{h}^{-1}$. Hence it is observed that the continuing loss varies with the duration of the storm rather than it remains constant throughout the storm. Similar characteristics are expected from other catchments around the world.

To examine the effect of duration on continuing loss an analysis was performed with all the selected 969 rainfall events using a threshold value of $0.01 \mathrm{~mm} \mathrm{~h}^{-1}$. To examine how continuing loss varies with the duration, the continuing losses of all the selected 969 rainfall events were plotted against their duration (duration between the end of initial loss and the end of the rainfall event) of all the events as shown in Fig. 2. The continuing loss for each catchment was examined against their durations of the remainder of the storm. It was observed that the continuing loss decays with duration i.e., it is not a single fixed value as recommended in $\mathrm{ARR}^{[4]}$.

In Queensland, the loss value varies with the location of the catchments. To examine the effect of duration in loss values for different regions of Queensland, the Queensland catchments were divided into two categories to compute storm losses such as eastern catchments and western catchments. The initial losses in western catchments are sometimes higher because the catchments are dryer than the eastern catchments. An investigation was performed to examine the effect of duration on continuing losses for different locations of Queensland catchments. Out of all selected 48 Queensland catchments 11 eastern catchments, 5 western catchments and 12 northern Queensland catchments were selected to examine the effect of duration on continuing loss values.

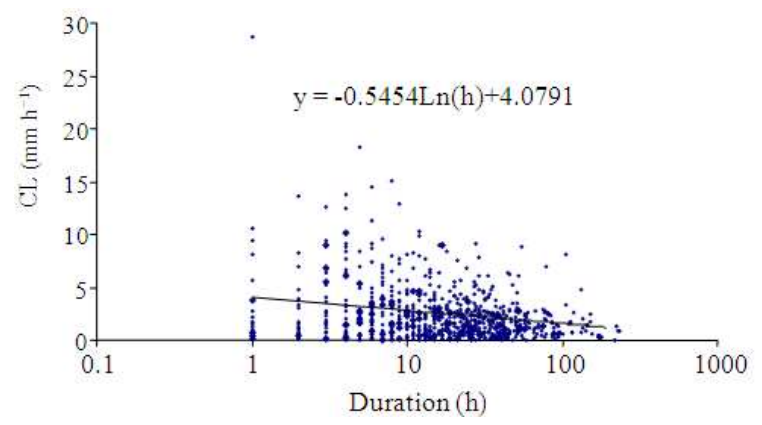

Fig. 2: Variation of continuing loss values with duration in all 48 selected Queensland catchments 
Am. J. Engg. \& Applied Sci., 2 (4): 796-803, 2009

Table 2: Descriptive statistics of the computed IL and CL values

\begin{tabular}{|c|c|c|c|c|c|c|c|}
\hline \multirow{2}{*}{$\begin{array}{l}\text { Catchment } \\
\text { ID }\end{array}$} & \multirow[b]{2}{*}{ Name } & \multirow[b]{2}{*}{$\operatorname{Area}\left(\mathrm{km}^{2}\right)$} & \multirow[b]{2}{*}{$\mathrm{N}$} & \multicolumn{2}{|c|}{ Storm Initial Losses (IL), mm } & \multicolumn{2}{|c|}{ Storm Continuing Losses (CL) $\mathrm{mm} \mathrm{h}^{-1}$} \\
\hline & & & & Range & Median & Range & Median \\
\hline 102101 & Pascoe river & 635 & 93 & $0.2-174.88$ & 37.61 & $0.05-13.67$ & 1.910 \\
\hline 104001 & Stewart river & 480 & 7 & $3.89-78.3$ & 42.17 & $0.9-6.59$ & 1.420 \\
\hline 105105 & E. Norman river & 300 & 3 & $10.92-18.39$ & 11.92 & $0.92-1.43$ & 1.300 \\
\hline 107001 & Endeavour river & 310 & 3 & $16.35-114.03$ & 71.77 & $0.57-3.07$ & 0.710 \\
\hline 107003 & Anna river & 247 & 3 & $12.24-36.46$ & 14.00 & $0.94-2.63$ & 1.490 \\
\hline 112003 & N. Johnston river & 173 & 15 & 3.3-108.55 & 34.04 & $0.3-7.79$ & 2.690 \\
\hline 112101 & S. Johnston river & 400 & 3 & $31.52-112.72$ & 41.66 & $2.68-4.48$ & 3.340 \\
\hline 114001 & Murray river & 155 & 23 & $1.6-159.22$ & 65.75 & $0.05-8.44$ & 4.740 \\
\hline 116008 & Gowrie river & 124 & 61 & $0.29-155.01$ & 21.74 & $0.01-10.29$ & 2.630 \\
\hline 116015 & Blunder creek & 127 & 48 & $1.92-189.37$ & 70.53 & $0.07-11.3$ & 1.460 \\
\hline 116017 & Stone river & 157 & 55 & $0.26-161.71$ & 33.23 & $0.09-14.52$ & 2.540 \\
\hline 118003 & Bohle river & 143 & 24 & $0.11-93.2$ & 28.80 & $0.66-7.63$ & 2.260 \\
\hline 119006 & Major creek & 468 & 4 & $10.27-79.87$ & 35.25 & $0.33-1.20$ & 1.150 \\
\hline 120014 & Broughton river & 182 & 19 & $2.0-71.0$ & 18.42 & $0.16-8.39$ & 2.060 \\
\hline 120216 & Broken river & 78 & 11 & $29.35-123.37$ & 64.26 & $0.56-9.11$ & 1.700 \\
\hline 124002 & St. Helens creek & 129 & 11 & $11.56-154.62$ & 53.71 & $0.33-6.04$ & 1.620 \\
\hline 125005 & Blacks creek & 505 & 35 & $0.8-144.39$ & 57.63 & $0.22-15.39$ & 3.450 \\
\hline 130207 & Sande creek & 409 & 14 & $3.84-97.04$ & 27.74 & $0.18-8.99$ & 2.680 \\
\hline 136108 & Monal creek & 92 & 12 & $2.71-48.2$ & 13.08 & $0.18-9.12$ & 1.210 \\
\hline 137101 & Gregory river & 454 & 8 & $3.57-123.05$ & 29.81 & $0.12-5.74$ & 2.035 \\
\hline 138110 & Mary river & 486 & 23 & $0.6-126.09$ & 29.95 & $0.1-4.01$ & 1.020 \\
\hline 141009 & N. Maroochy river & 38 & 22 & $1.52-113.26$ & 42.27 & $0.16-3.71$ & 0.890 \\
\hline 143110 & Bremer river & 125 & 37 & $0.24-116.98$ & 39.04 & $0.02-12.55$ & 1.170 \\
\hline 143212 & Tenhill creek & 447 & 24 & $6.86-125.46$ & 43.48 & $0.01-7.58$ & 1.160 \\
\hline 145003 & Logan river & 175 & 42 & $0.2-99.01$ & 30.82 & $0.07-18.31$ & 1.460 \\
\hline 145010 & Running creek & 128 & 20 & $0.0-80.57$ & 31.86 & $0.01-10.17$ & 1.180 \\
\hline 145011 & Teviot brook & 83 & 37 & $1.5-91.9$ & 29.70 & $0.01-6.99$ & 1.000 \\
\hline 145101 & Albert river & 169 & 35 & $0.59-165.84$ & 43.46 & $0.01-6.95$ & 1.520 \\
\hline 146014 & Back creek & 7 & 10 & $0.0-49.55$ & 4.84 & $0.52-2.92$ & 1.870 \\
\hline 416410 & Macintyre brook & 465 & 28 & $0.05-93.34$ & 28.73 & $0.15-15.06$ & 1.770 \\
\hline 422321 & Spring creek & 35 & 6 & $0.24-40.41$ & 4.29 & $0.05-1.76$ & 0.730 \\
\hline 422338 & Canal creek & 395 & 27 & $0.07-116.41$ & 24.24 & $0.13-6.84$ & 1.580 \\
\hline 422394 & Cadamine river & 325 & 21 & $8.99-89.35$ & 40.51 & $0.08-3.2$ & 0.920 \\
\hline 913005 & Paroo creek & 305 & 6 & $1.06-25.64$ & 9.31 & $0.64-5.58$ & 2.380 \\
\hline 913009 & Gorge creek & 248 & 9 & $0.03-46.23$ & 6.20 & $0.17-5.39$ & 1.060 \\
\hline 915205 & Malbon river & 425 & 5 & 9.1759 .79 & 34.21 & $0.56-14.61$ & 3.950 \\
\hline 916002 & Norman river & 285 & 9 & $0.66-102.63$ & 16.61 & $0.54-5.63$ & 3.200 \\
\hline 916003 & Moonlight creek & 127 & 7 & $0.51-60.58$ & 28.93 & $0.45-10.4$ & 2.400 \\
\hline 917005 & Agate creek & 228 & 19 & $0.14-34.67$ & 13.90 & $0.23-7.12$ & 2.830 \\
\hline 917007 & Percy river & 445 & 8 & $0.11-24.85$ & 24.49 & $0.04-5.02$ & 1.920 \\
\hline 917107 & Elizabeth creek & 585 & 8 & $2.74-42.09$ & 27.25 & $0.25-4.03$ & 2.040 \\
\hline 917114 & Routh creek & 81 & 7 & $6.57-61.03$ & 29.55 & $0.67-4.06$ & 1.440 \\
\hline 919201 & Palmer river & 530 & 5 & $1.82-55.86$ & 38.31 & $0.08-8.62$ & 2.200 \\
\hline 919205 & N. Palmer river & 430 & 7 & $0.8-46.19$ & 14.51 & $0.3-10.95$ & 5.800 \\
\hline 921001 & Holroyd river & 365 & 16 & $1.91-90.31$ & 39.29 & $0.26-16.04$ & 1.190 \\
\hline 922101 & Coen river & 166 & 59 & $0.26-81.89$ & 24.52 & $0.08-9.45$ & 2.160 \\
\hline 926002 & Dulhunty river & 325 & 12 & $0.0-6.29$ & 3.39 & $0.03-5.91$ & 1.600 \\
\hline 926003 & Bertie creek & 130 & 8 & $0.0-5.03$ & 0.70 & $0.18-6.85$ & 1.640 \\
\hline Average & & & 20 & $0.0-189.37$ & $0.7-71.77$ & $0.01-18.31$ & $0.71-5.8$ \\
\hline
\end{tabular}

To examine how continuing loss varies with duration, the continuing loss and the duration of 270 rainfall events of 11 eastern Queensland catchments were plotted as shown in Fig. 3. It shows that, the continuing loss is not constant with storm duration but rather it decays with the duration. The equation of the decaying curve is shown in Fig. 3.

In Fig. 4 the continuing losses of 96 rainfall events of 5 western catchments in Queensland are plotted against their respective durations to examine 
the effect of duration on continuing losses. Figure 4 shows that the continuing loss is not constant in respect of duration, but it decays with respect to duration of the rainfall event. The equation of the decaying curve is also shown in Fig. 4.

In Fig. 5 the continuing losses of 340 rainfall events of 12 northern catchments of Queensland are plotted against their respective durations to examine the effect of duration on continuing losses. Figure 5 shows that the continuing loss is not constant in respect of duration, but that it decays with respect to duration of the rainfall event. The equation of the decaying curve is shown in Fig. 5. Also the results of the continuing losses against their durations for few individual catchments are shown in Fig. 6.

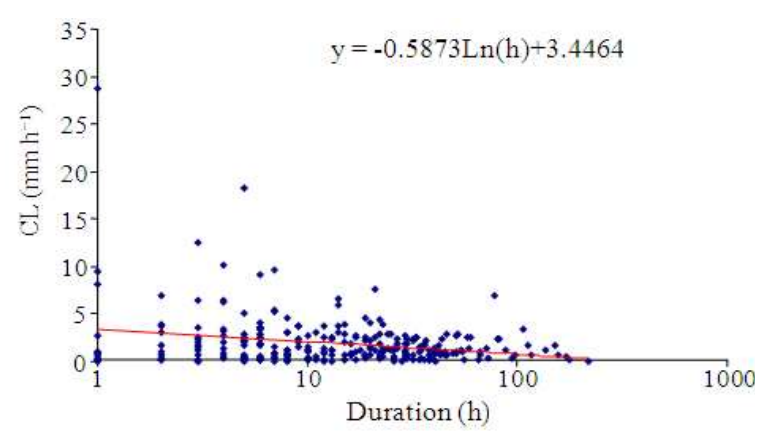

Fig. 3: Variation of continuing loss values with duration in 11 eastern Queensland catchments
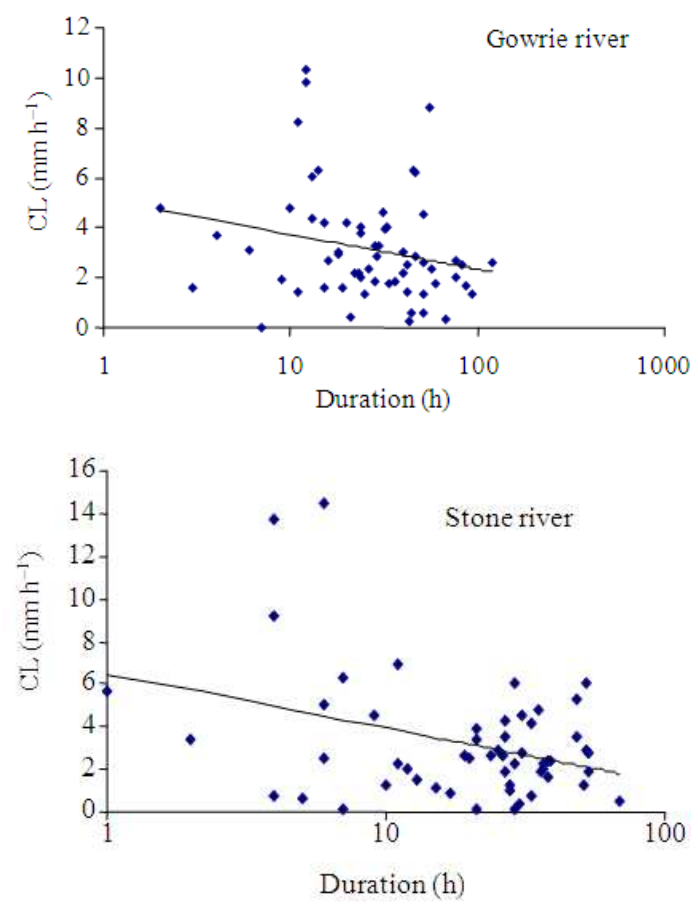

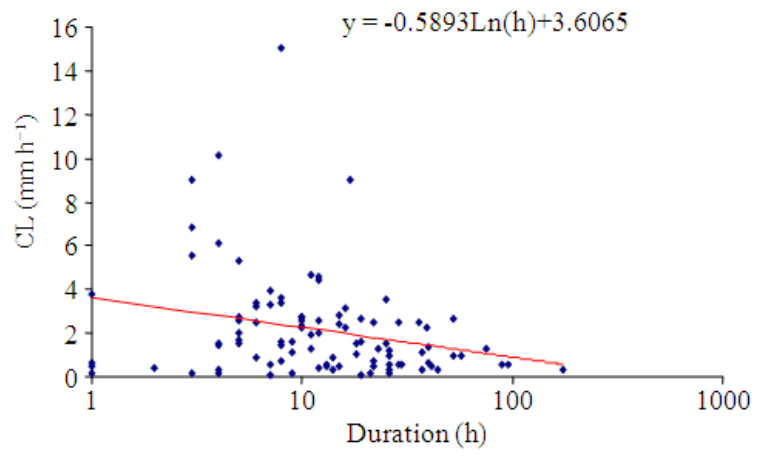

Fig. 4: Variation of continuing loss values with duration in 5 western Queensland catchments

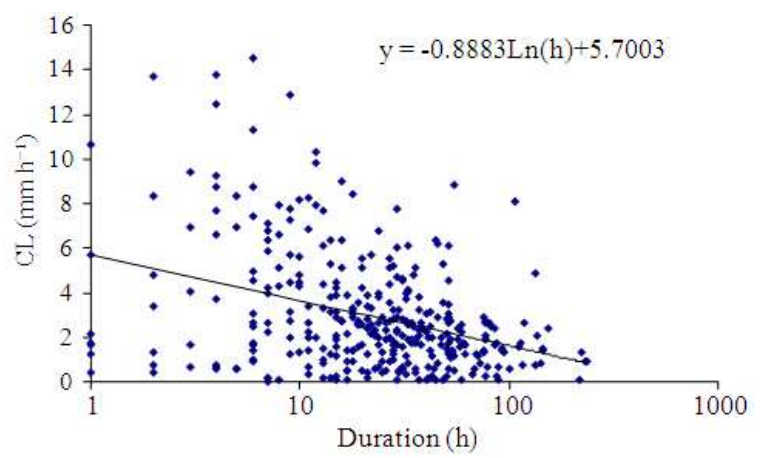

Fig. 5: Variation of continuing loss values with duration in 12 northern Queensland catchments
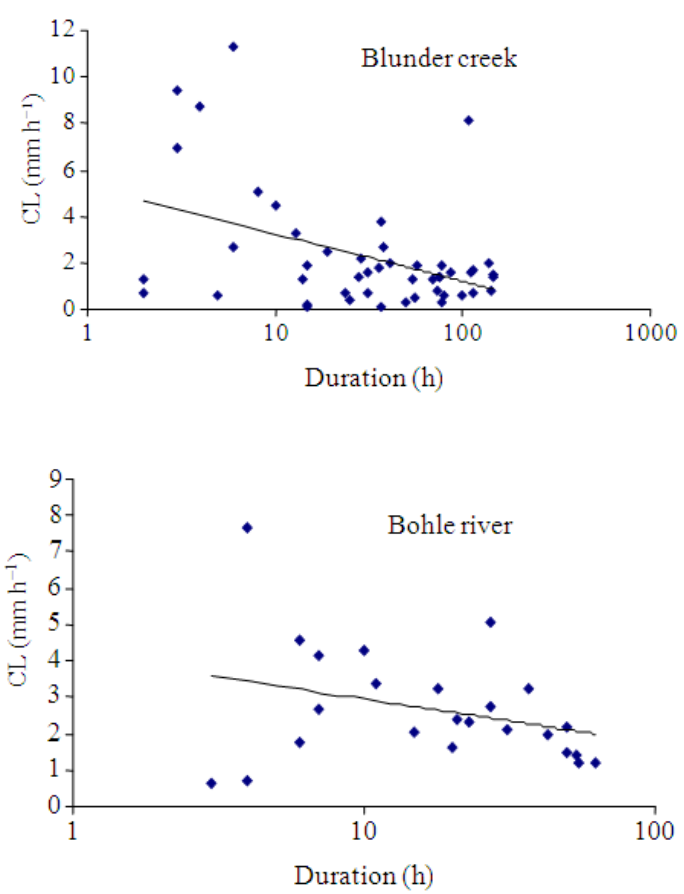
Am. J. Engg. \& Applied Sci., 2 (4): 796-803, 2009
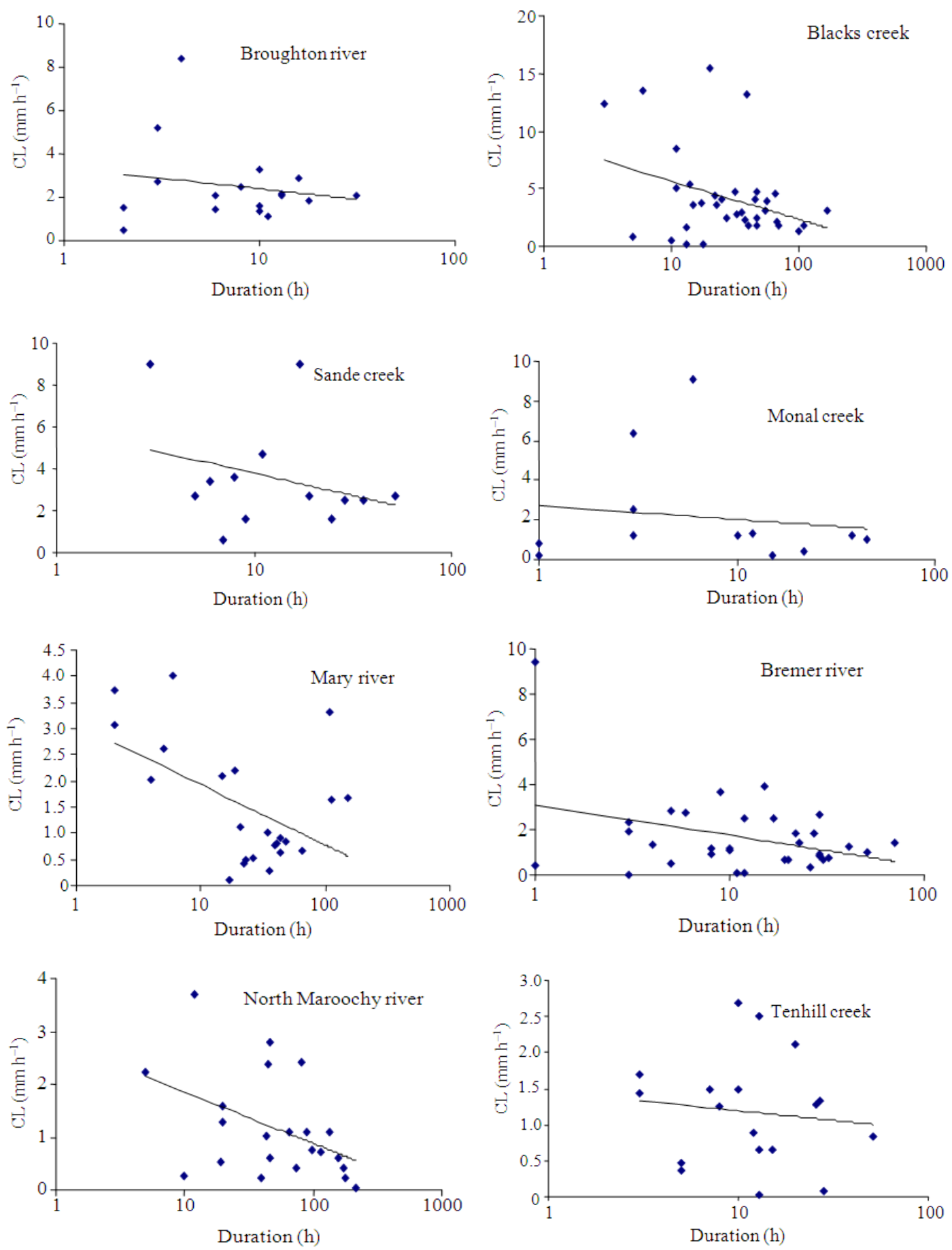

Fig. 6: Plots of continuing losses against their durations for few individual catchments

\section{DISCUSSION}

IL-CL model and associated parameters are widely used in Australia for design flood estimations. Current design practice is to use $\mathrm{ARR}^{[4]}$ recommended region specific values. $\mathrm{ARR}^{[4]}$ recommended that continuing loss rate is constant throughout the duration of the storm. However, using many years of data, derived continuing 
losses values found in this study are not constant. Rather, it is found that continuing loss value decreases with the increase of the duration of the rainfall event i.e., CL value is not a fixed single value for a catchment as recommended in $\mathrm{ARR}^{[4]}$ but it decays with the increase in the duration of the storm. Hence, it was observed that the continuing loss of the Queensland catchments can be described as probability distributed losses.

\section{CONCLUSION}

This research analyzed how to improve the design continuing loss estimate for flood estimation in Queensland. The finding has important significance for design flood estimation. The following conclusions can be drawn from the analysis:

- It was observed that the computed median CL value for western Queensland catchments was $12.86 \%$ higher than that of ARR recommended median continuing loss value

- It is recommended in ARR that the continuing loss that occurs for a rainfall event is at a constant rate during the remainder of the storm. But this recommendation is not correct as per Fig. 2-6, which proved that the continuing loss decreases with the time i.e., it is not a single fixed value during the remainder of the storm. Hence, the continuing losses for the Queensland catchments are in reality probability distributed losses

- This finding (probability distributed losses) is required to be confirmed with a larger data set. A larger data set is required to derive stochastic continuing losses for application with Joint Probability Approach as described by Ilahee et al. ${ }^{[3]}$

\section{REFERENCES}

1. Hill, P.I. et al., 1996. Empirical Analysis of Data to Derive Losses for Design Flood Estimation in South-Eastern Australia. Cooperative Research Centre for Catchment Hydrology, ISBN: 1876006110, pp: 98.

2. Hiscock, K., 2005. Hydrology Principles and Practice. Willy-Blackwell Publishing, Oxford, UK., ISBN: 10: 0632057637, pp:408.

3. Ilahee, M., A. Rahman and W.C. Boughton, 2001. Probability-distributed initial losses for flood estimation in Queensland. Proceedings of the International Congress on Modeling and Simulation, Dec. 10-13, Canberra, Australia, pp: 107-112. http://eprints.qut.edu.au/24622/

4. Institution of Engineers Australia, 1998. Australian Rainfall and Runoff: A Guide to Flood Estimation. Institution of Engineers Australia, Australia, ISBN: 0858254360.

5. Laurenson, E.M. and D.H. Pilgrim, 1963. Loss rates of Australian catchments and their significance. J. Inst. Eng. Aust., 35: 9-24.

6. Rahman, A., P.E. Weinmann and R.G. Mein, 2002. The use of probability-distributed initial losses in design flood estimation. Aust. J. Water Resour., 6: 17-30. http://www.eabooks.com.au/epages/eab.sf/en_au/? ObjectPath=/Shops/eabooks/Products/AJWR019

7. Snorasson, A., H.P. Finnsdottir and M.E. Moss, 2002. The Extremes of the Extremes: Extraordinary Floods. IAHS Publication, UK., ISBN: 10: 190150266X, pp: 408.

8. Werner, M., 2001. Uncertainty in flood extent estimation due to uncertain parameters. Proceedings of the Congress-International Association for Hydraulic Research (CIAHR'01), Netherlands, pp: 360-367. 